\title{
HOJAS EMBETUNADAS Y LIBROS EN PAPEL: ESCRITURA Y MEMORIA PERSONAL EN LA ESPANA MODERNA
}

\author{
Antonio Castillo Gómez \\ Universidad de Alcalá - España
}

Resumen: En este trabajo se analizan las escrituras privadas de los siglos XVI y $X V I I$ en cuanto herramientas para el recuerdo y espacios de configuración de la memoria personal, familiar y social. Se repasan sus manifestaciones más representativas y cotidianas, en particular, las diversas tipologías de libros de memoria, los libros de cuentas y las memorias propiamente dichas. En cada caso se consideran las características materiales de los distintos escritos, su contenido y las funciones que pudieron cumplir.

Palabras clave: escritura, España moderna, memoria personal, memoria social.

Abstract: In this work are analyzed the private writings of XVIth and XVIIth centuries like tools for the memory and spaces of configuration of the personal, familiar and social memory. It reviews their more representative and daily manifestations, in individual, and the different types of memory books, the account books and the memoirs. In each case are considered the material characteristics of different writings, their content and the functions that they could make.

Keywords: modern Spain, personal memory, social memory, writing.

Sabido es que la carta, de la que me he ocupado con anterioridad (Castillo, 2002a), acredita una de las prácticas más significativas de la escritura personal durante el Siglo de Oro. Pero en aquella sociedad donde, como anotó Juan de Ycíar en su Ortographía Prática (1548, f. 1r.), ya no se podía ni sabía vivir sin el ejercicio del escribir, las dimensiones de dicho campo comprenden igualmente otra suerte de escritos que, en cierto sentido, funcionaron como objetos-memoria; es decir, como herramientas para el recuerdo e instrumentos para la expresión de las identidades personales y 
colectivas (Mandingorra, 2002, p. 131). Por más que muchas no hayan llegado hasta nosotros, la variedad de las escrituras producidas, y eventualmente conservadas, en el ámbito doméstico sugiere la posibilidad de que con ello se pretendiera constituir y transmitir una cierta memoria individual y familiar. Guardadas en arcas o en gavetas de escritorios, incluían, junto a documentos notariales, como testamentos y actas matrimoniales, otros testimonios de naturaleza estrictamente personal. Una ojeada al cofre de la mujer de Samuel Pepys sirve para acercarnos a algunos filones de esa memoria a la vez que nos advierte de su intrínseca fragilidad:

Esta mañana, en cama, mi mujer volvió a hablarme de la necesidad de una dama de compañía. Si ella permite a las criadas familiaridades que las echan a perder es, dice, porque no tiene otra compañía. Cierto, demasiado cierto. Llamó a Jane y le dio las llaves de su cofre para que sacara un rollo de papeles, de los cuales se puso a leer uno. Ahí describe en inglés, en términos muy vivos, con detalles casi siempre exactos, la soledad de su vida y la tristeza que la envuelve. La idea de que ese papel pudiera ser encontrado y leído por extraños me enfadó sobremanera. Le rogué, le ordené que lo rompiera. Se negó. Tuve que tomarlo por la fuerza; lo rompí; después me apoderé del resto del paquete. Saltando de la cama en camisón, los metí en los bolsillos de mi pantalón para que no los cogiera. Luego, habiendo ordenado mis medias, mi pantalón y mi bata, saqué los papeles uno tras otro y los hice trizas ante sus ojos, bien que a pesar mío, pues ella lloraba y me imploraba que me detuviera. Pero yo estaba demasiado encolerizado. ¡Ver mis cartas de amor, el testamento por el cual le había legado todo lo que tenía en el mundo antes de salir a navegar, junto a ese papel tan humillante y deshonroso! Cuando hube destrozado todo, salvo mi licencia de matrimonio y la primera carta que le escribiera cuando era su cortejante, recogí los fragmentos y los llevé a mi escritorio. Después de reflexionar mucho si iba o no a quemarlos, terminé por recoger los trozos del papel que me había leído y los de mi testamento, luego quemé el resto y partí hacia la oficina lleno de confusión. (Pepys, 2003, p. 110-111). 
Quien fuera secretario del Almirantazgo, miembro del Parlamento inglés y presidente de la Real Sociedad observó, según vemos, distintos criterios respecto a la conservación de los papeles del matrimonio. Mientras que guardó buena parte de los suyos, como los voluminosos diarios que redactó entre 1660 y 1669, hizo trizas una sustanciosa porción de los que su mujer había atesorado o escrito. Con ello pretendía levantar un muro de silencio sobre algunos avatares de la vida matrimonial procurando que su honor no se viera socavado por la soledad y la tristeza de su mujer.

Ya fuera porque se quisiera preservar algún secreto, porque no siempre se juzgara importante conservar dichos papeles o porque con ello se buscara establecer una cierta memoria de uno mismo; lo cierto es que la destrucción de las escrituras privadas revela aspectos notables del valor depositado en ellas al igual que impone algunas rémoras para su estudio, sobre todo cuando se quiere analizar la concreción material del hecho de escribir.

Contando con ello, lo que sigue es una aproximación a algunos de los contenidos y formas materiales donde se fue plasmando la memoria personal más urgente: unas veces con la inmediata necesidad de combatir transitoriamente los contratiempos del olvido; y otras con la voluntad, más o menos firme, de preservar el testimonio o de transmitir una experiencia de vida, incluso una página de historia. La indagación se queda a las puertas de otros procesos más exploratorios del yo, no exentos tampoco de alguna atención literaria, caso de las autobiografías propiamente dichas.

\section{Tablillas, hojas embetunadas y libros en papel}

Empezando por los librillos de memoria, últimamente tan de moda, es oportuno señalar que su precedente más directo está en algunos prototipos medievales bastante parecidos. Dejando aparte que el uso de las tablillas enceradas haya sido una constante a lo largo de la historia - ora para usos escolares, ora para la composición de los más variados escritos (cartas, testamentos, inventarios, etc. (Lalou, 1992) -, procede traer a colación ese apunte del siglo VII donde se refiere que, durante su visita a varios conventos, el santo Juan Climaque se topó con un monje encargado del refectorio que "llevaba en su cintura unas tablillas pequeñas en las que escribía cada día todos los pensamientos que tenía a fin de dar cuenta exacta de ellos al abad”. Varios siglos después, Felipe el Hermoso empleó un códice 
compuesto por seis tablillas de madera enceradas para consignar sus cuentas domésticas del segundo semestre de 1308 (Lejeune; Bogaert, 2003, p. 25-26).

El monje se valió de aquellas para apuntar momentáneamente las inquietudes y pecados que luego había de confesar al superior; en tanto que el rey francés utilizó un soporte muy similar para dejar memoria de otros asuntos más mundanos. En suma, dos casos coincidentes de un escritura huidiza, sin tinta, para borrar; como la que se apunta en la siguiente copla de un caballero que, para componer unos motes, se recogió a pensar y escribir (Zapata, 1959, p. 380-381):

La pluma muy bien cortada

Y el papel muy bien bruñido,

Y el galán muy retraído,

Mucho quedará corrido

Si después no dice nada.

Porque suele acontecer

Sobre mucho aparejar,

Cuando más es menester

Borrar lo escrito de ayer,

Y escribir para borrar.

En su forma y uso, las mencionadas tablillas guardaban un alto parentesco con los libros, libricos o librillos de memoria empleados durante la Edad Moderna. Sobre todo con los más próximos a la definición que de esa voz propuso el Diccionario de Autoridades (1990, II, p. 400):

El librito que se suele traher en la faltriquera, cuyas hojas están embetunadas y en blanco, y en él se incluye una pluma de metal, en cuya punta se inxiere un pedazo agudo de piedra lápiz, con la qual se annota en el librillo todo aquello que no se quiere fiar a la fragilidad de la memoria; y se borra después para que vuelvan a servir las hojas, que también se suelen hacer de marfil.

El cervantino libro de Cardenio constituye la primera de las autoridades alegadas por la Academia. La otra se toma de una de las comedias de Calderón, El Conde Lucanor, donde a la sazón se cita varias veces el "libro 
de memoria dorado” que Pasquín llevaba en la faltriquera y donde tenía escritas algunas confidencias personales: "Es vn libro de memoria, / que traigo en la faltriquera"; "Mira que es mi confessión, / no le abras, no le leas” (Calderón, 1674, f. 225-226). Adviértase, de paso, que la descripción académica recoge datos sustanciales para la reconstrucción material del objeto aludido: un soporte de formato pequeño que se podía llevar en la faltriquera, con las hojas de madera embetunadas o incluso de marfil, y acompañado de una pluma de metal con la punta de carboncillo. Así mismo, Sebastián de Covarrubias (1984, p. 798), en su definición de "memorioso", equipara el "libro de memoria" con los "pugillares latine, vel palimpsestus”. En suma, un producto gráfico bastante análogo a las writing tables conocidas en Inglaterra entre 1570 y 1630 (Chartier; Mowery; Stalybrass; Wolfe, en prensa).

Dichos libros de memoria eran bastante usuales entre los cortesanos áureos, según puede constatarse por los estudios de Bouza (2003a) y Gonzalo (2004). Inventarios, documentos y fragmentos literarios referidos a ellos destilan no pocas menciones a polípticos de pizarra, guarnecidos en cuero, oro, plata, marfil o con telas preciosas, dotados de herrajes y manecillas de plata, bronce u oro, y que a veces estaban iluminados, sobre todo en las guardas de las cubiertas, amén de llevar incorporado el lápiz metálico con punta de carboncillo o alguna "piedra blanca", barita de yeso o tiza, para escribir. Así, a principios de 1544, el joven Felipe II mandó pagar 204 maravedís al librero madrileño Juan de Medina por la encuadernación de "vn librico de memoria de piedras negras guarneçido de plata en madera y cuero negro” (AGS. CSR. Leg. 36, 1ํ, f. 41r.; Gonzalo, 2004). Treinta años después todavía conservaba cuatro de éstos, entre ellos uno "chiquito con cubierta de marfil y dos tachones de plata”, al que le faltaba la mano, según consta en el Catálogo de los Libros de su Mag. [Felipe II], que se Hallaron en Poder de Serojas, fechado en marzo de 1575 (RBME, \&-II15, f. 308v.; Gonzalo, 2004). Igualmente, en su inventario de bienes se menciona un "librico a manera de libro de memorias", tasado en 4 ducados, compuesto por "siete hojas de tabla", con una piedra de diversos colores encajada en medio de cada tabla, "y en las dos, antiguallas de plata, redondas, con caracteres de diversas letras”, que incluía en cada hoja el "título de la virtud que cada piedra tiene y, entre las hojas, unos tafetanes verdes”, aparte de estar "encuadernado en cuero negro, con una guarnición 
y un clavico de plata que la cierra” (Sánchez Cantón, 1956-1959, § 4807). José Luis Gonzalo Sánchez-Molero (2004) ha apuntado que su introducción en la corte española "estuvo claramente vinculada con un uso previo en Alemania y los Países Bajos”. Fuera de los “çinco libricos para escribir memorias, el vno dellos de hueso blanco e los otros dos de cuerno, las cubyertas estoriadas y el de hueso blanco tiene vnos escudos de las armas rreales y el otro está desenquadernado y fáltanle media qubyerta, que estaba tasado cada vno a dos rreales”, incluidos en la almoneda de Isabel la Católica (1505), llegados probablemente de Flandes y vendidos a mosén Felipe por tres reales (Torre, 1974, p. 114); dicho autor considera que pudo ser su hija, la reina Juana, quien trajera la moda a la península Ibérica. Observa que en el inventario de sus bienes, realizado en 1509, se incluyeron “dos libros de debuxar", de los cuales "vno tenía cubiertas de marfil y el otro hera de horas de molde", mencionados de nuevo y casi en los mismo términos en 1555; sin embargo, cuando la herencia pasa a Carlos V la descripción que se hace resulta más expresiva: "vn libro de memorias chiquito, y pluma, vn rretablillo pequeño de las ystorias de la pasión de bulto, es de marfil todo figuras y tablas, bien fecho en blanco". A su lado habría que estimar el ejemplar de su hijo, el infante don Fernando, hermano de Carlos V, de quien se conserva, en el museo del castillo de Ambras en Tirol, un libro en forma de políptico de pizarra con anotaciones suyas, en castellano, referidas a su entorno más íntimo, datadas entre 1526 y 1530. En la cubierta ostenta, en la parte externa, su escudo como soberano de Hungría; y en la interna, vistas de una de sus residencias, probablemente el castillo de Praga, obra del artista Johann Minsinger fechada en 1529 (Opll; Rudolf, 1997, p. 51-53).

Quitando que algunos fueran particularmente suntuarios, la condición de joyas es común a los ejemplares aristocráticos. Entre los varios testimonios que pueden traerse a colación, indican ese carácter: el "librico de memoria con las tablas de plata y vna manezica con vn punçón con que se çierra”, de la emperatriz Isabel (1539) (Gonzalo, 2004); sendos libros de memoria de Brianda de la Cerda y Sarmiento, duquesa de Béjar, uno "enquadernado de colorado" y otro "con unas manezillas de oro" vendido por 50 reales, recogidos ambos en su inventario de 1602 (Dadson, 1998, p. 424, 430); el "librito de memorias con cerradura y llave" de la librería de Ana Piñeiro Manrique, condesa de Puñonrostro, tasado en 2 reales (1616) (Dadson, 
1998, p. 446); u otro “con sus maneçillas y palillo de oro”, valorado en cuatro ducados, de Duarte de Portugal, marqués de Frechilla, registrado en su inventario de 1627 (Bouza, 2003a, p. 52; 2003b, p. 281). Incluso podría ser el caso del "librico de azabache dorado" de Ana de Salazar, esposa del mercader Juan de Ortega, que tanto podía tratarse de un credo o relicario para guardar nóminas u oraciones como de un ejemplar similar a un "librico de asentar memorias”, también suyo (Cátedra; Rojo, 2004, p. 182, 245).

Por ello que la elaboración de muchos de estos libros fuera tarea más de orfebres que de libreros. Concretamente, el relojero Juan de Serojas y el platero Manuel Correa intervinieron en el rematado del que Felipe II encargó en 1544, pues el segundo recibió 340 maravedís a cuenta de "unas manos de plata para un libro de memoria que avía guarneçido Serojas y le puso una hoja de piedra y un garfio de piedra"; mientras que dos años después hallamos al relojero enfaenado en otro "librico de memoria con tres tablas de piedra negra guarneçidas de oro por las orillas” (AGS, CSR, Leg. 36, $1^{\circ}$, fs. 41v. y 181v.; Gonzalo, 2004). De "lindísimo" calificó el Duque de Lerma uno de los libros de memoria que, en 1601, recibió de su tío Juan de Borja, conde de Mayalde y Ficallo, para entregarlo al rey:

Beso las manos a Vuestra Señoría por el libro de memoria que es lindísimo, y otro como el que Vuestra Señoría me dio por zierto trayo siempre conmigo, y por eso daré éste a Su Magestad. (BL. Add. 28424, f. 101v-102r; García García, 1996, p. 265).

Tales libros tampoco debían ser muy diferentes a algunos de los que se vendían en Valladolid en la segunda mitad del siglo XVI. Recuérdese que, en 1563, se podían adquirir "libros de memoria de piedra” y "libros de piedra guarnecidos” en la tienda de Pablo Estaqueres; y que, treinta años después, Miguel Navarro vendía en la suya "libros de memoria dorados". Por supuesto también los había de hechura más modesta, designados por su tamaño, como los libros de memoria medianos y pequeños que se ofrecían en 1554 en el comercio de Fansín de Villanueva (Rojo, 1996, p. 259). Así mismo la Tassa reformada de 1628 distinguía entre los "libros de memoria blancos", ajustados en 28 maravedís, y los "libros de memoria dorados mejores y colorados”, a real y medio cada uno (Tassa..., 1628, f. 13r.).

Todo apunta a que la misma denominación valía para designar objetos distintos. La variante más próxima a la evocada en el Diccionario de 
Autoridades estaba representada por los polípticos de pizarra, hojas embetunadas y papeles muy bien bruñidos donde se practicaba esa “escritura para borrar”, que decía Luis de Zapata. Abundando en la función conferida a tales librillos de memoria, Felipe III disponía de uno donde apuntaba "todas las mercedes, assí personales como generales, que Dios le avía hecho después que entró en la Monarchía”; amén de tomarlo cada día, en el retiro de la oración, para leer y repasar todos los beneficios inscritos en sus páginas, agradeciéndoselos a Dios uno por uno y sumando nuevas oraciones (García García, 1996, p. 11; Peñalosa, [s.d.]). En la tragicomedia El Premio de la Hermosura, de Lope de Vega (1981, p. 1520-1521), Mitelene alude a ellos cuando dice que los ojos, "como libros de memoria, / van apuntando deseos, / pretensiones amorosas, / sentimientos y esperanzas”. A su vez, Celinos, uno de los forasteros que visitan la corte de los Austrias en la obra de Liñán y Verdugo, anotaba en el suyo las informaciones más variopintas antes de trasladarlas a un soporte más duradero:

Celinos, antes que se le acabase el dinero, comenzó a entablar sus enredos y embustes, que no fueron tantos como los de Pedro de Urdemalas; compró un librillo de memorias, íbase por las calles de Madrid, y encontrándose a algún caballero o hidalgo forastero de buen hábito, pegábase a uno de los criados o pajes de los que le parecía que llevaban la boca más abierta, pisaba más a lo zambo, informábase de quién era su señor, qué negocios tenía en Corte, qué pleitos o pretensiones, ante qué tribunal, cuál era su apellido y linaje, qué renta comía, en qué calle posaba, hasta hacer la información de manera que no le dejaba hueso sano, y antes de perderlo de la memoria, remitíalo a la de su libro, y de allí lo trasladaba en su casa con pluma y tinta a su libro grande a modo de los de caja, debe y ha de haber.

Otras veces se iba al patio de palacio por las mañanas, a las tardes a las comedias o al prado, casas de conversación, trucos u otros juegos, a donde mezclándose a lo que allí se trataba y haciéndose amigo de algunos, les sacaba del pecho sus intentos, sus negocios, sus pesadumbres, con que dentro de pocos meses, escribiendo esto como lo demás en el libro de caja, se vino a hacer dueño, entre otras cosas, de algunos pleitos y pretensiones de esta Corte. (Liñán, 1980, p. 157158). 
En este punto es pertinente recuperar una observación formulada por fray José de Sigüenza a principios del siglo XVII. Al describir los fondos judíos de la biblioteca de El Escorial, menciona la existencia en ella de un "pugilar antiguo de los mismos hebreos, en que, como nosotros en el breviario o capitulario, tenían las lecciones y cosas de la Santa Escritura que se leían más frecuentemente en sus sinagogas”, aparte de emplearlo para asentar sus cosas particulares, "como nosotros en los libros que llamamos de memoria” (Sigüenza, 1988, p. 431). De nuevo, la pluralidad semántica del vocablo admite pensar tanto en un ejemplar concebido para una escritura fugaz como en otro destinado a una fijación más estable. A la postre, la misma que puede alegarse del librillo de memorias donde don Quijote había pergeñado el borrador de la carta que Sancho debía llevar a Dulcinea del Toboso. ¿De qué librillo se trataba?

Cervantes lo describe como un ejemplar "ricamente guarnecido" que don Quijote y Sancho encontraron, cabalgando por Sierra Morena, en el interior de una maleta. Iba acompañado de cuatro camisas de "delgada holanda”, es decir, de un lino muy fino, otras piezas de lienzo no menos primorosas y un montoncillo de escudos de oro. Al abrirlo para intentar desvelar la identidad del dueño, lo primero que don Quijote "halló en él, escrito como en borrador, aunque de muy buena letra, fue un soneto". Animado por el escudero a seguir curioseando en su interior llegó a un texto en prosa que parecía una carta. “¿Carta misiva?”, le preguntó Sancho. “En el principio no parece sino de amores”, le respondió don Quijote, quien, "hojeando casi todo el libro, halló otros versos y cartas, que algunos pudo leer y otros no; pero lo que todos contenían eran quejas, lamentos, desconfianzas, sabores y sinsabores, favores y desdenes, solenizados los unos y llorados los otros” (Cervantes, 1998, I, p. 252-254).

A partir de ahí el hidalgo manchego no se separará del librillo, lo llevará consigo y lo hará propio. Donde Cardenio había anotado versos y prosas de lastimado amor, él añadirá textos varios. Sabemos que en una ocasión apuntó allí la cédula de los pollinos con la que quiso compensar a Sancho del hurto de su rucio, y en otra el citado borrador de la carta que el escudero debía entregar a Dulcinea:

Sacó el libro de memoria don Quijote y, apartándose a una parte, con mucho sosiego comenzó a escribir la carta, y en acabándola llamó a 
Sancho y le dijo que se la quería leer porque la tomase de memoria, si acaso se le perdiese por el camino, porque de sus desdicha todo se podía temer. A lo cual respondió Sancho:

- Escríbala vuestra merced dos o tres veces ahí en el libro, y démele, que yo le llevaré bien guardado; porque pensar que yo la he de tomar en la memoria es disparate, que la tengo tan mala, que muchas veces se me olvida cómo me llamo. Pero, con todo eso, dígamela vuestra merced, que me holgaré mucho de oílla, que debe de ir como de molde. (Cervantes, 1998, I, p. 286).

Unos capítulos más adelante, Sancho, interrogado por su señor, confirmará que nadie le pudo trasladar la carta porque el borrador de la misma estaba en el "librillo de memoria" y éste se quedó en las manos de don Quijote:

Así es como tú dices - dijo don Quijote -, porque el librillo de memoria donde yo la escribí le hallé en mi poder a cabo de dos días de tu partida, lo cual me causó grandísima pena, por no saber lo que habías tú de hacer cuando te vieses sin carta, y creí siempre que te volvieras desde el lugar donde la echaras menos. (Cervantes, 1998, I, p. 356-357).

Estos detalles subrayan la posibilidad de que dicho librillo viniera a remediar la fugacidad de la memoria mediante una serie de apuntes que luego se pudieran borrar. Es cierto que la mención de este ejemplar en la definición académica del término podría apuntalar dicha hipótesis; pero tampoco debe omitirse que la descripción cervantina no termina de precisar si el librillo de Cardenio estaba compuesto de hojas embetunadas y blancas; si se trataba de algún políptico de pizarra; si sería más bien como el "librico de memoria” de hojas negras de la Condesa de Miranda (1544) (Cátedra; Rojo, 2004, p. 221) o incluso como el "papel negro que sin pluma ni tinta se escribe con un palillo puesto debajo en papel blanco", mencionado por Luis de Zapata entre otras invenciones nuevas (Zapata, 1959, p. 357); si se parecería a las piezas ricamente guarnecidas, con manecillas o llaves, atesoradas en las casas nobles; o si consistiría en uno de tantos libros en papel encuadernados para “asentar memorias” (Cátedra; Rojo, 2004, p. 181- 
182). Es más, hasta podría pensarse que Cervantes introduce cierta confusión al descartar como materia de la que estuviera fabricado tanto el papel como las hojas de los árboles o las tablillas de cera, tan difíciles de encontrar como el primero:

Todo irá inserto - dijo don Quijote -; y sería bueno, ya que no hay papel, que la escribiésemos, como hacían los antiguos, en hojas de árboles o en una tablillas de cera, aunque tan dificultosa será hallarse eso ahora como el papel. Más ya me ha venido a la memoria dónde será bien, y aun más que bien, escribilla, que es en el librillo de memoria que fue de Cardenio, y tú tendrás cuidado de hacerla trasladar en papel, de buena letra, en el primer lugar que hallares donde haya maestro de escuela de muchachos, o, si no, cualquiera sacristán te la trasladará. (Cervantes, 1998, I, p. 282).

Esta posible equiparación entre el librillo y otros soportes de escritura efímera, el carácter de borrador de algunos de los textos copiados en sus páginas o la mención de autoridad por la Academia podrían llevarnos a emparentarlo con la modalidad correspondiente a los polípticos de hojas embetunadas o cualesquiera otras superficies donde se pudiera escribir y borrar. Sin embargo, conforme se ha precisado, no debe soslayarse que la voz librillo de memoria se empleaba igualmente para designar otras prácticas de escritura más estables, efectuadas en cuadernos de papel. A este respecto, es oportuno recordar una de las definiciones que se dieron de la voz "memorias" en el Diccionario de Autoridades: "Se llama también el libro, quaderno, papel u otra cosa, en que se apunta o annota alguna cosa para tenerla presente y que no se olvide: como para escribir alguna Historia u otra cosa”.

\section{Libros de cuenta y razón}

Por eso, sin necesidad de abandonar el rico imaginario cervantino, el librillo de memoria de Monipodio indicaría justamente el contrapunto. Casi al final de Rinconete y Cortadillo, Cervantes narra el momento en que Monipodio saca el librillo que llevaba en la "capilla de la capa” y se lo da a leer a Rinconete, porque él no sabía. Éste lo toma en sus manos y 
encuentra que aquellas páginas contenían todo un registro del afanoso laboreo de los bajos fondos sevillanos. En el recto del primer folio figuraba un único asiento bajo la rúbrica "Memoria de las cuchilladas que se han de dar esta semana"; después la "Memoria de palos"; y luego el "Memorial de agravios comunes":

Fuese muy satisfecho el caballero, y luego Monipodio llamó a todos los ausentes y azorados. Bajaron todos, y poniéndose Monipodio en medio dellos, sacó un libro de memoria que traía en la capilla de la capa, y dióselo a Rinconete que leyes, porque él no sabía leer. Abrióle Rinconete, y en la primera hoja vio que decía:

\section{MEMORIA DE LAS CUCHILLADAS QUE SE HAN DE DAR ESTA SEMANA}

La primera, al mercader de la encrucijada: vale cincuenta escudos. Están recebidos treinta a buena cuenta. Secutor, Chiquiznaque.

[...]

Volvió la hoja Rinconete, y vio que en otra esta escrito: Memoria de palo. Y más abajo decía:

Al bodeguero de la Alfalfa, doce palos de mayor cuantía a escudo cada uno. Están dados en buena cuenta ocho. El término, seis días. Secutor, Maniferro.

$[\ldots]$

- Pues pasad más adelante - dijo Monipodio -, y mirad donde dice: Memorial de agravios comunes.

Pasó adelante Rinconete, y en otra hoja halló escrito:

Memorial de agravios comunes, conviene a saber: redomazos, untos de miera, clavazón de sambenitos y cuernos, matracas, espantos, alborotos y cuchilladas fingidas, publicación de nibelos, etcétera. (Cervantes, 1992, p. 235-236).

De acuerdo a tan detallada descripción del contenido resulta claro que dicho librillo era de un pago y tenor bien distintos al de Cardenio. Todo apunta a un libro de cuentas integrado por una sucesión de registros breves, ajustados al fluir de los días y al discurrir de los negocios o actividades consignados en sus páginas. Cada "memoria” estaba anotada en una hoja distinta de modo que la información estuviera más organizada y accesible y 
en cada momento se pudiera conocer el estado de las cuchilladas, palos o agravios, pendientes o ya ejecutados. De vuelta a El Quijote, en éste hallamos referencia a otro de parecido calibre, aquel donde Dorotea llevaba la administración de la hacienda paterna, labradores ricos en Andalucía:

Y del mismo modo que yo era señora de sus ánimos, ansí lo era de su hacienda: por mí se recebían y despedían los criados; la razón y cuenta de lo que se sembraba y cogía pasaba por mi mano, los molinos de aceite, los lugares del vino, el número del ganado mayor y menor, el de las colmenas; finalmente, de todo aquello que un tan rico labrador como mi padre puede tener y tiene, tenía yo la cuenta y era la mayordoma y señora, con tanta solicitud mía y con tanto gusto suyo, que buenamente no acertaré a encarecerlo. (Cervantes, 1998, I, p. 321-322).

Tales testimonios exhiben el eco literario alcanzado por estos libros cuyo contenido podía transitar entre las anotaciones que no se querían dejar al albur de la memoria y aquellos productos más pensados para el asiento de las cuentas, de los recuerdos personales y de familia o, incluso, de otros de alcance más social. Volviendo ahora a la documentación coetánea, basta con echar un vistazo a los inventarios notariales para confirmar su amplia presencia en el ámbito privado. Por mencionar algunos testimonios, podríamos pensar en el "libre de recort scrit de mà" del mercader Simón Godinella (1549), en el "libre de comptes scrita de mà” del doncel Melcior Felisses (1595) o en los “dos libres en paper cuberts de pergamí de comptes y memòries” del cerero Francesc Juliol (1550), todos ellos de Barcelona (Peña, 1996, p. 127-128). Así como en los testimonios aragoneses relativos a un ejemplar "con cubiertas de pergamino del año 1654, que comienza 'memoria de las deudas que deben en la botiga'”, a otro también encuadernado en pergamino "que comienza 'Jesús, María, Joseph: lista de las personas que deben en esta’ y acaba con un quaderno cosido al rebés con estas palabras 'ajustóse en 14 de junio de 1683'” o, por no citar más, a un tercero "intitulado 'de Memoriis' del año mil seyscientos quarenta y quatro” (Navarro, 2003, p. 810-811).

Adviértase que tanto la denominación de algunos de éstos como la referencia a su contenido o la enumeración más detallada de los asuntos inscritos en el cervantino de Monipodio coinciden en aducir la palabra 
"memoria". Es cierto que ésta, cuando se refiere a tal suerte de libros, no entrañaba necesariamente una escritura de índole autobiográfica (Peña, 1996, p. 144); pero sin que por ello debamos desestimarlos como elaboraciones culturales de una determinada mirada de sí (Amelang, 1998, p. 22-51). Indudablemente, dicha expresión alude, sobre todo, a un tipo de libro, también llamado de razón, en el que la persona, mayormente un administrador o un comerciante, "escribe todo lo que recauda y gasta para darse cuenta y razón a sí mismo de todos sus negocios” (Foisil, 1991, p. 332).

Fue, en efecto, la necesidad de registrar los cobros y los pagos o el nombre de los deudores y acreedores, conforme se hizo constar en la cubierta de alguno de los libri di famiglia medievales, lo que desencadenó una cierta extensión social de la capacidad de escribir y la difusión de estos productos, especialmente desde mediados del siglo XIV (Allegrezza, 1991; Castillo, 2002b, p. 198-203). Aunque sus principales usuarios fueron los artesanos y mercaderes, también los utilizaron hacendados y campesinos acomodados. Del repertorio bajomedieval, el libro de ricordi de los campesinos toscanos Meo y Benedetto del Massarizia y varios livres de raison franceses o provenzales son muestra clara de su extensión en el mundo rural. Entrando en la Edad Moderna, no debe perderse de vista la notable nómina catalana, donde está atestiguada su presencia en 22 familias de payeses durante los siglos XVI y XVII, al igual que otros ejemplares pertenecientes a granjeros ingleses y de los Países Bajos (Balestracci, 1984; Franceschini, 1990; Klapisch-Zuber, 1991; Tricard, 1988; Slicher van Bath, 1962; Stoklund, 1980; Torres, 2000).

Otro dato que certifica esta proyección es su presencia entre las mercaderías del pobre buhonero muerto hacia 1575 en el hospital de Villerías de Campo (Palencia). En el inventario de sus bienes, extendido el 24 de noviembre por el escribano Juan García, se constata que, junto a ciertas imágenes, algunos libros, "un pergamino de cubiertas de libro" y enseres varios, también llevaba consigo "dos libros de quentas” y un "librillo pequeño de quentas” (Arroyo, 1999, p. 251). Según esto ya no se trataba sólo de que las gentes de las ciudades pudieran adquirirlos en tiendas y otros puntos de venta; sino que, además, engrosaron el mercado característico de los vendedores ambulantes junto a la quincallería, los libros de oraciones, las estampas y los pliegos de cordel. 
A diferencia de los librillos de memoria ricamente guarnecidos, esta otra modalidad tenía una hechura mucho más corriente. Lo atestiguan tanto los ejemplares conservados como determinadas descripciones notariales especialmente clarificadoras:

Yten paresçe por vn libro de quarto de pliego que <e>stá escripto de la mano del dicho liçençiado Alonso de Deça, que aya gloria, en que dize por él en çiertos capítulos que <e>stán escriptos en çinco hojas e rubricadas del dicho señor contador, en que por ella paresçe que prestó el dicho liçençiado Alonso de Deça al dicho Lope de Deça çiertos maravedís, e que ansimismo cobró por él, e ansimismo paresçe en la quenta que se hiço ante Castro, e de lo mismo que está en estas çinco hojas, e porque no está feneçido en la dicha quenta antel dicho Castro e de lo cargamos e hazemos cargo dello aquí en la manera siguiente:

- Paresçe por el dicho libro que le prestó en el primero capítulo dél, quinze mill maravedís para pagar a la madre de Teresa López, muger que fue de Baldomero; no dize en que día ni mes ni año [...]. (Castillo, 1997, p. 307).

Escritos en vulgar eran, por lo común, libros de pequeño formato, normalmente entre octavo y cuarto, compuestos por varios cuadernillos de papel y encuadernados a lo sumo con una pieza de pergamino, extraída a veces de la página de algún libro, como si con ello se quisiera dotarlos de mayor consistencia y preservar mejor el texto. Puede verse en esto una voluntad de memoria sugerida igualmente por las rúbricas empleadas en la denominación de estos productos - memoria, ricordi, ricordanze - y por las fórmulas invocadas para introducir la toma de la escritura: entre otras, "Sia a mi memoria" o "Memòria sia a mi”, empleadas respectivamente en los libros del notario Françesc Ferrando y de Miquel Ferrer (Mandingorra, 2002, p. 134).

Normalmente su contenido estaba formado por un cúmulo de registros breves y estereotipados, conforme a una estructura diplomática a menudo inspirada en los hábitos notariales. Podían estar redactados por el propietario, si estaba alfabetizado, o valiéndose de un intermediario gráfico, cuando no era así o no podía hacerlo por cualquier otra circunstancia. Antes 
de allegarnos al Siglo de Oro, tal modalidad fue la empleada por los campesinos Meo y Benedetto del Massarizia, padre e hijo, en sus dos libritos de cuentas. En sus páginas no encontramos la huella escrita de sus analfabetos propietarios, pero sí la de un amplio ramillete de compaisanos que trataron con ellos (Balestracci, 1984). El mismo procedimiento fue adoptado en la elaboración del librillo de cuentas de la tendera romana Magdalena, cuyos 102 registros fueron anotados por los respectivos deudores y acreedores o por sus dependientes y representantes (Petrucci, 1978).

De similar factura pero redactados por sus titulares son, entre otros, los ejemplares de los estudiantes salmantinos Gaspar Ramos Ortíz y el italiano Girolamo da Sommaia. Al primero corresponde un libro-diario donde llevó su cuenta personal de gastos mientras estuvo dicha Universidad entre 1568 y 1569), como él mismo se encarga de advertir al comienzo: "En este libro está la raçón de los mrs. que yo Gaspar Ortiz, hijo legítimo de los muy mgcos. mis señores padres Balthasar Ramos Ortiz y Catalina Álvarez su muger que aya gloria, voy gastando y pagando en esta Universidad de Salamanca”, siendo su contenido justamente ese (Rodríguez-San Pedro, 1999, p. 33). Algo similar es el "diario" compuesto por Girolamo entre enero de 1603 y julio de 1607, si bien los volúmenes que lo integran merecen algunas apreciaciones. $\mathrm{Al}$ inaugurar el primero, su titular se refiere a él como "libellus rationarium", y, en efecto, su tenor y estructura son típicos de los libros de cuenta y razón; mientras que el segundo, llamado "libro ad formam Ephimerides seu Diarij", combina las notas de ese tipo con otras sin cargo monetario referidas a sus actividades estudiantiles y sociales (visitas, lecturas, correspondencias cursadas, sermones escuchados, actos universitarios, etc.), aproximándose más a la forma textual del diario personal (Sommaia, 1977).

Otra variante seguida en la confección de estos productos consistió en la reunión de un conjunto de recibos. En vez de anotar expresamente cada uno de los ingresos o pagos efectuados se optó por incorporar directamente el albarán, de forma que el libro pasaba a desempeñar los cometidos de un archivo doméstico. Tal procedimiento se puede intuir en la descripción notarial de los "quern ab cuberts de pergamins en lo qual hia continuats albarans e algunas memòrias de poca importància” (1546) del pelaire Salvador Palleres, o, en 1590, en la del libro de memorias del pasamanero Joan Rovira, "en lo qual stan scrites quinze cartes ab alguns albarans, y les altres blanques” (Peña, 1996, p. 129-130, 144). En un terreno más empírico,

Horizontes Antropológicos, Porto Alegre, ano 10, n. 22, p. 37-65, jul/dez. 2004 
lo atestigua el ejemplar contemporáneo intitulado Libro de la señora doña María de Mendoza, siendo ésta la hermana de Íñigo López de Mendoza, marqués de Mondéjar. Este manuscrito contiene una serie de recibos, fechados entre 1575 y 1581, relativos a la administración de los bienes de dicha dama; y otros, datados entre 1583 y 1602, correspondientes a los pagos y censos de su sobrina Catalina, hija natural del citado Marqués, criada con su tía, vecinas ambas de Alcalá de Henares (AHN, Clero, Jesuitas, Leg. 36, núm. 11). Como en otros casos similares, el libro y su transmisión familiar pueden tomarse como una manera de organizar, establecer y legar tanto el patrimonio como la memoria del grupo.

El libro en cuestión está compuesto por seis cuadernillos de tamaño cuarto, encuadernado con un folio de pergamino extraído de un códice medieval, seguramente de una obra litúrgica o de un cantoral, y debidamente anudado (Cortés, 1998, p. 403-404). En su interior se fueron cosiendo los recibos que conforman la memoria económica de estas mujeres de la nobleza castellana sin que en ello mediara criterio cronológico alguno. De hecho, el libro se abre con un recibí de 1584 suscrito por Juan de Garay, mayordomo del Colegio de san Ildefonso de Alcalá de Henares, relativo a las gallinas que Catalina de Mendoza había satisfecho del censo que debía pagar por Navidad; mientras que poco más adelante figura otro, datado a 23 de julio de 1575, acreditando el abono de uno de los plazos del censo perpetuo contraído por María de Mendoza con el concejo de la villa. Sólo en algunas páginas encabezadas por el nombre de la persona beneficiaria de los pagos se aprecia un principio de organización más racional.

Éste, sin embargo, resulta más evidente en aquellos libros de cuentas y memorias que dispusieron de algún sistema clasificatorio, como un abecedario previo remitiendo al folio donde se extiende el asiento del gasto o asunto aludido. Este dato se comenta, por ejemplo, de esa "graciosa cosa" que llevaba consigo la conocida alcahueta Margaritona cuando la prendieron; a la sazón, un "libro de pliego entero" que, de haber existido, representaría una interesante variedad de esta familia de librillos:

Dícese que le hallaron una graciosa cosa, es a saber: un libro de pliego entero, hecho de retratos, con su abecedario, número, calle y casa, de las mujeres que querían ser gozadas, donde iban los señores, y los que no lo eran también, a escoger, ojeando, la que más gusto les daba, donde se dice había gente de muy buen porte de todos estados, y 
zurcidoras de honras tan bien como de paños desgarrados. (Barrionuevo, I, 1968, 6-IX-1656).

Por lo que se intuye podía tratarse de un libro muy semejante al que Cervantes atribuye a Monipodio y Antonio de Solís a otro rufián no menos famoso, el doctor Carlino. En un momento de la segunda jornada de la comedia, éste sale a escena con uno en la mano y dispuesto a repasar los negocios en los que andaba metido, que eran más o menos del siguiente aspecto: "Calle Mayor, casamiento, cien escudos de contado, mil si se acierta; recado de atrevido pensamiento” (Solís, 1951, p. 47-48). El de Margaritona tenía una doble peculiaridad: por una parte, los "retratos”, como si fuera una suerte de álbum de meretrices; y por otra, el abecedario empleado para ordenar la información recogida. Es la misma característica que debía reunir el libro de memorias del presbítero Pere Guanser, que “comensa any 1566 ab un abecedari”, según se encargó de reflejar el notario que inventarió sus bienes (Peña, 1996, p. 128).

Fuera de toda hipótesis, la inclusión del índice alfabético es precisamente uno de los rasgos que presenta el libro donde el mercader zaragozano Felipe Los Clavos registró sus cuentas de 1588 a 1647 (ADPZ, Ms. 623). En éste, por ejemplo, la rúbrica dedicada a la letra "m" se abre con el asiento "Mygel de Fillera, beçino de Yjea de los Caballeros, en folio 8”, y, efectivamente, dicho folio contiene detallada la "memoria de lo que yo e gastado por Miguel de Fillera, natural de la bila de Exea de los Caualeros". Aunque no siempre se siguiera un mismo criterio de alfabetización, pues tanto podía valer un nombre de persona como la materia objeto del asiento o la palabra que encabezara éste, su sola incorporación expresa una cierta racionalización del registro escrito con el fin de allanar la búsqueda de información, en suma, de servirse del libro como soporte de la memoria económica y a veces personal.

Cuando un mismo individuo, sobre todo en el caso de los propietarios, administradores y comerciantes, precisó de varios libros de cuentas, lo normal es que fueran anuales. Es una posibilidad que señalan aquellos registros notariales donde se menciona el año al referirlos, como en varios de los consignados en el inventario de las escrituras que, en mayo de 1662, estaban en poder del licenciado José Luis de Aínsa (Navarro, 2003, p. 811). Todavía es más probable que las descripciones de este porte aludan a la primera de las cuentas registradas o al título anotado en la cubierta, aunque 
luego su contenido pudiera incorporar datos referidos a los años previos y posteriores. Sucede así en el Llibre del ofisi de molines de vent de la Seva als 23 agost, any 1691 (bnm, Mss. 18347), un ejemplar de tamaño cuarto, en papel y guarnecido con pergamino, en el que figuran registros tanto anteriores a la fecha señalada en la cubierta como las cuentas correspondientes a Jaume Bover, titular del cargo, entre 1690 y 1717.

\section{Memoria familiar versus crónica social}

Volviendo al libro de cuentas de Felipe Los Clavos, es de notar ahora el contenido de ciertas entradas relativas a la letra "m" del índice. Amén de la cuenta de Miguel de Fillera, se introducen dos apuntes de defunción del siguiente tenor:

murió mi suegra, questé con los ánjeles, martes a dos días del mes de junio del año de nuestro señor Jesuchristo de mil y seisçientos y quatro.

murió aquella santa de mi fija, Agostina Los Clabos, que goçe para sienpre con todos los santos en la gloria, amén, lunes a doçe de julio del año de nuestro señor Jesuchristo de mil y seisçientos y quatro. (ADPZ, Ms. 623, f. 13r.).

La instrumentación del objeto como espacio de configuración familiar tiene su mayor demostración en los libros de familia, donde la escritura se sucede de unas generaciones a otras conformando la genealogía y la memoria del grupo (Cicchetti; Mordenti, 1985; Mordenti, 2001). Incluso, llegado el caso, con cierta voluntad instructiva y ejemplar, como la que expuso el cronista y doctor en derecho Jeroni Pujades en el prefacio de su dietario:

Y porque nuestra naturaleza es mortal, como nos enseña la experiencia [...] y así no podemos perpetuarnos para poder contar y hacer saber a nuestros hijos y sucesores lo que pasa en nuestro tiempo, por esto es bueno escribir y dar continuidad a lo que hoy acontece, para que por medio de la escritura se puede saber en el 
futuro. (Simon, 1991, p. 21).

Procurando "poder contar y hacer saber" cuanto pasaba en su tiempo, el pelaire Gaspar Gasset no perdió la oportunidad de hacer constar en su libro de memorias el embarque del emperador Carlos $\mathrm{V}$ o los fastos relativos a la celebración del Corpus en Valencia en 1544; mientras que en la continuación a cargo de su hijo Josep predominan las anotaciones de índole familiar: nacimientos, matrimonios y defunciones. A su vez, Miquel Ferrer destinó algunas páginas del suyo a dar memoria de las fiestas celebradas en Valencia en julio de 1622 por la canonización de varios santos (Mandingorra, 2002, p. 135-137).

Un caso bien significativo es el que nos ofrece el "diario" del payés Joan Guàrdia, campesino hacendado de Santa María de Corcó (l’Esquirol), completado con algunos apuntes de su hijo Antoni Joan. Si observamos su comienzo, comprobamos que, tras hacerse con un "llibre de paper blanch", el autor se dispone a dejar memoria de sus "comtas" y "negosis" a partir del primero de diciembre de 1631. Al comienzo, todo apunta hacia un típico libro de cuentas, máxime considerando que los folios iniciales contienen una serie de anotaciones de tal cariz fechadas entre ese día y el 2 de noviembre de 1639. A continuación, sin embargo, se consignan el natalicio de seis hijos, comenzando por el de Ana María Petronila, y la firma de las capitulaciones matrimoniales de su hermano. Prosiguen los registros de cuentas, salpicados con algún asiento de tono distinto - como el relativo a la muerte de su boyero Joan Riera y determinados ejercicios de álgebra de Antoni Joan, su hijo -, hasta que en el recto del folio 27 se incorpora el pormenorizado relato de una "cosa miracolosa del que s'à socseït aquest any de 1687 en aquest lloch de l'Asquirol", a saber, "l'aspant que la gent an tingut de una plaga de llagostas” (Pladevall; Simon, 1986, p. 54-56).

Aunque las “comtas y negosis” vuelvan alguna que otra vez, lo que sigue es un diario más volcado en la memoria colectiva. Se da cuenta de los hechos más significativos de cada año, los avatares históricos, las pestes y hambrunas, las celebraciones festivas, el paso de un cometa y, señaladamente, el desarrollo de la guerra de los segadores. Aparte de ciertos desastres familiares, como la muerte de varios cuñados, la suegra, la hermana o algunos de sus hijos.

El diario de Joan Guàrdia representa así un testimonio ejemplar del trasvase y de las conexiones entre la memoria personal y la colectiva, así 
como de la voluntad de trascendencia depositada en la primera. En algunos escritos personales dicho salto se explicita más claramente en la intitulación del texto, sobre todo cuando incorporan términos como "memorias", “noticias” o "relación”. En tal sentido pueden considerarse, entre otras, las Memòrias per a Sempre (1551-1573) del caballero Perot de Vilanova (Simon, 1991); los dos volúmenes manuscritos, De Molts Sucessos que han Succeït dins Barcelona i en Molts Altres Llochs de Catalunya Dignes de Memòria (1626-1660), del zurrador barcelonés Miquel Parets (BUB, Mss. 224-225); las Notícies de València i son Regne (s. XVII) de mosén Joaquim Aierdi (1999); las Coses Evengudes en la Ciutat i Regne de València (1589-1628) de mosén Pero Joan Porcar (1934); o el “diario” de Antonio Moreno de la Torre, merino mayor de la ciudad de Zamora, escrito entre 1673 y 1679 (AHPZ, Fondo Moreno de la Torre, Leg. 1).

Todos ellos, y otros más que se podrían agregar, reflejan una actividad memorialista volcada en la crónica social (García Cárcel, 1993; Escartí, 1998). Normalmente la narración se nutre de cuanto el autor ha visto o sabido; pero también es usual que se enriquezca y contraste con el argumento que aportan cartas, relaciones y otra suerte de materiales documentales que se suelen alegar, copiar o resumir. Por ello que muchas de estas memorias sean el vivo espejo de una práctica de escritura sensiblemente más rica y elaborada, en la que también son claros los vínculos entre los actos de escribir y de leer (Castillo, 2004, p. 32-33). A propósito de este asunto, Antonio Moreno de la Torre se sirvió de los panfletos, la literatura de cordel y la poesía callejera en su crónica zamorana; mosén Joaquim Aierdi, de relaciones de sucesos, en la suya de Valencia y su reino; y el presbítero Gregorio Martín de Güijo (1952, p. 128), secretario de la Iglesia metropolitana de México, de algunos escritos probatorios como el edicto de la devoción a la Virgen del Rosario.

En cuanto prácticas de escritura, las memorias de este cariz testimonian, en términos generales, una competencia desplegada en torno a dos ejes: habilidad gráfica y organización del discurso. Si, para empezar, tomamos como botón de muestra el diario del merino zamorano, lo primero está probado por la esmerada ejecución del trazo y la distribución del texto en la superficie de los folios donde escribe; lo segundo, puede verificarse observando la arquitectura textual, levantada sobre dos pilares organizativos: la sucesión cronológica de los apuntes y el uso de notas marginales para 
destacar los hechos y materias recogidos, aparte de otras donde queda constancia de la lectura y revisión del manuscrito.

Un procedimiento análogo es el que puede observarse en las Memòrias per a Sempre de Perot de Vilanova. De un lado, debe destacarse que, al tiempo de redactarlas, el autor se valió de diversos materiales, particularmente documentos coetáneos. De otro, el texto de Perot de Vilanova se divide, hasta un cierto punto, en parágrafos numerados, introducidos por la fórmula "Not" (Notum), de procedencia notarial. La racionalización del escrito se completa con la inserción de notas marginales alusivas al contenido.

La segmentación del discurso y su representación en unidades menores perfectamente marcadas y nombradas es una característica que también constatamos en otras memorias de personas habituadas a escribir, ya sean las de Frederic Despalau (Simon, 1991); el libro de memorias (1572-1602) de Jeroni Saconomina, ciudadano de Gerona, donde "estan asentades algunes jornades y notas de cosas que an per mi pasades y tanbé del temps que jo hera diputat del real de Catalunya, y tanbé parla de jornades que alguns parens y estranys són nats y morts y tanbé de alguns casamens que·s són fets de persones, parentes y estranyes, y tanbé parle d'altres coses molt difarens” (Simon, 1991, p. 189); o las de Miquel Parets. En éstas, puede notarse la cuidada cursiva usual en la que escribe, signo claro de un hábito que se materializa en la significativa extensión de las mismas. Igualmente debe reseñarse la importante organización del texto, de la que dan cuenta tanto las múltiples divisiones y rótulos internos, como las llamadas marginales al contenido o las letras capitulares empleadas para realzar distintos comienzos. Incluso cuando transcribe algún documento oficial en apoyo de sus recuerdos, trata de hacerlo reproduciendo su disposición gráfica. Miquel Parets, en suma, manifiesta, en todo momento, una elevada competencia escrituraria.

Por el contrario, manuscritos como el Llibre de Comtas y Negocis de Joan Guàrdia o la pequeña libreta de la familia Perai, dueños de un mesón en la población de Esquirol, cuyos apuntes, escritos seguramente por Salvador Perai y su hijo Josep Perai, combinan los asientos contables, desde 1579, con las anotaciones de historia local, centradas en el período 16881709 (Pladevall; Simon, 1986), dejan ver una escritura menos estructurada y seguramente más inmediata, ligada al ritmo fijado por la memoria cotidiana; así como una menor competencia gráfica, visible en las 
incorrecciones ortográficas o en la general falta de puntuación.

Más allá de los pormenores gráficos, esta clase de textos evidencian una escritura girada hacia el futuro y planteada en términos claramente testimoniales; esto es, como si sus autores estuvieran pensando en la historia, según dijo Ignasi Terradas. Señala este autor, tratando de las memorias de las masías catalanas, que, de algún modo, el mayorazgo se sentía atraído por el conocimiento histórico y acostumbraba a hablar del presente con un lenguaje del pasado, siendo desde esa perspectiva desde la que "las grandes pérdidas, las guerras, las hambrunas, los desastres, las muertes, etc., eran vividas en el presente como si fuesen ya un recuerdo. Como historia” (Terradas, 1984, p. 335). A fin de cuentas casi lo mismo que vino a decir Jeroni de Capmany en el prólogo a la crónica gerundense del noble Jeroni de Real:

para que en el futuro algunos de esta ciudad se puedan valer y tomar ejemplo de lo que en ella se contó, esto es, de muchas cosas dignas de toda estimación y memoria que han pasado a lo largo del tiempo. (Simon, 1991, p. 22).

Cosas dignas de toda estimación y memoria que alcanzaron su objetivo al ser desparramadas sobre páginas de papel en blanco mediante el fértil concurso de la escritura. Mientras que hubo quienes no alcanzaron a redactar nada más que algún cuadernillo; otros dispusieron de la condición necesaria para transmitir un testimonio más amplio y hasta elaborado, incluso con la posibilidad de repartirlo en diversos objetos-memoria:

En el orden económico tenía mi padre un sistema que yo sé alabar mas no imitar; y era que además del registro de los negocios de la casa donde se anotan cuentas menudas, pagos, compras que no exigen intervención del notario, registro que tiene a su cargo un administrador, ordenaba llevar un diario a uno de sus criados que sabía escribir, en el cual se insertaban todos los acontecimientos destacables, y día a día, las memorias de la historia de su casa, muy amena de ver cuando el tiempo comienza a borrar los recuerdos y muy adecuada para sacarnos de dudas muy a menudo: ¿Cuándo se empezó tal obra? ¿Cuándo se terminó?, ¿Qué servidumbre pasó por allí? ¿Quiénes se quedaron? Nuestros viajes, nuestras ausencias, 
desposorios, muertes, la llegada de buenas o malas noticias; el cambio de los principales criados; materias semejantes. (Montaigne, 1985, I, p. 287).

Antigua costumbre, añade Montaigne, que "deberíamos desenterrar, cada cual a su modo", al tiempo que se llamaba necio "por no haberlo hecho". Cuando escribe estas palabras está pensando en el diario que no llegó a escribir, pues su lacónico Efemérides de Beauther apenas si merecería tal categoría. Samuel Pepys lo hizo con más propiedad, mientras que otras muchas personas, notables y gente común, puede que exploraran esa vía a través de los libros de cuentas, libros de familia y memorias, considerados en estas páginas, testigos de una escritura híbrida donde aquel habría tenido su origen (Castillo, 2001, p. 821-829).

\section{Abreviaturas}

ADPZ - Archivo de la Diputación Provincial de Zaragoza

AHN - Archivo Histórico Nacional

AHPZ - Archivo Histórico Provincial de Zamora

BL - British Library

BNM - Biblioteca Nacional de Madrid

BUB - Biblioteca Universitaria de Barcelona

RBME - Real Biblioteca del Monasterio de El Escorial

\section{Referencias}

AIERDI, Joaquim. Dietari: notícies de València i son regme, de 1661 a 1664 i de 1667 a 1679. Edición de Vicent J. Escartí. Barcelona: Barcino, 1999. ALLEGREZZA, Franca. La diffusione di un nuovo prodotto di bottega: ipotesi sulla confezione dei libri di famiglia a Firenze nel Quattrocento. Scrittura e Civiltà, 15, p. 247-265, 1991.

AMELANG, James S. The Flight of Icarus: artisan autobiography in Early Modern Europe. Stanford: Stanford University Press, 1998.

ARROYO RODRÍGUEZ, Luis A. Las mercancías de un vendedor de pliegos de cordel de la segunda mitad del siglo XVI. Bulletin Hispanique, 
101, p. 247-251, 1999.

BALESTRACCI, Duccio. La zappa e la retorica: memorie familiari di un contadino toscano del Quattrocento. Firenze: Salimbeni, 1984.

BARRIONUEVO, Jerónimo de. Avisos (1654-1658). Edición y estudio preliminar A. Paz y Melia. Madrid: Atlas, 1968. (Biblioteca de Autores Españoles, 221-222).

BOUZA, Fernando. Palabra e imagen en la Corte: cultura oral y visual de la nobleza en el Siglo de Oro. Madrid: Abada, 2003a.

BOUZA, Fernando. En la corte y en la aldea de D. Duarte de Braganza: libros y pinturas del Marqués de Frechilla y Malagón. Península: Revista de Estudos Ibéricos, 0, p. 261-288, 2003b.

CALDERÓN DE LA BARCA, Pedro. El Conde Lucanor. In: QUINTA parte de comedias de... Madrid, 1674.

CASTILLO GÓMEZ, Antonio. Escrituras y escribientes: prácticas de la cultura escrita en una ciudad del Renacimiento. Las Palmas de Gran Canarias: Gobierno de Canarias-Fundación de Enseñanza Superior a Distancia, 1997.

CASTILLO GÓMEZ, Antonio. Entre public et privé: stratégies de l'écrit dans l'Espagne du Siècle d'Or. Annales: Histoire, Sciences Sociales, 56 année, n. 4-5, p. 803-829, 2001.

CASTILlO GÓMEZ, Antonio. "Como o polvo e o camaleão se transformam": modelos e práticas epistolares na Espanha Moderna. In: BASTOS, Maria Helena C.; CUNHA, Maria Teresa S.; MIGNOT, Ana Chrystina V. (Org.). Destino das letras: história, educação e escrita epistolar. Passo Fundo: Universidade de Passo Fundo, 2002a. p. 13-55.

CASTILLO GÓMEZ, Antonio. Entre la necesidad y el placer: la formación de una nueva sociedad del escrito (ss. XII-XV). In: CASTILLO GÓMEZ, A. (Coord.). Historia de la cultura escrita: del Próximo Oriente Antiguo a la sociedad informatizada. Gijón: Trea, 2002b. p. 179-270.

CASTILLO GÓMEZ, Antonio. La biblioteca interior: experiencias y representaciones de la lectura en las autobiografías, memorias y diarios del Siglo de Oro. In: CÁTEDRA, Pedro M.; LÓPEZ-VIDRIERO, Mª Luisa (Dir.). La memoria de los libros: estudios sobre la historia del escrito y de la lectura en Europa y América, tomo II. Salamanca: Instituto de Historia del Libro y de la Lectura, 2004. p. 15-50.

CÁTEDRA, Pedro M.; ROJO VEGA, Anastasio. Bibliotecas y lecturas de mujeres: Siglo XVI. Salamanca: Instituto de Historia del Libro y de la 
Lectura, 2004.

CERVANTES, Miguel de. Rinconete y Cortadillo. In: CERVANTES, Miguel de. Novelas ejemplares. Ed. Harry Sieber. Madrid: Cátedra, 1992.

CERVANTES, Miguel de. Don Quijote de la Mancha. Ed. del Instituto Cervantes dirigida por Francisco Rico. Barcelona: Instituto CervantesCrítica, 1998.

CHARTIER, Roger; MOWERY, Frank; STALYBRASS, Peter; WOLFE, Heather. Hamlet's Tables ad the Technology of Writing in Renaissance England. Shakespeare Quarterly. En prensa.

CICCHETTI, Angelo; MORDENTI, Raul. I libri di famiglia in Italia, I: filologia e storiografia letteraria. Roma: Edizioni di Storia e Letteratura, 1985. CORTÉS CORRAL, Mónica. Prácticas privadas de escritura en Alcalá de Henares: el libro de recibos de María y Catalina de Mendoza (1575-1602). In: Encuentro de historiadores del Valle del Henares, 6., 1998, Alcalá de Henares. Actas... Alcalá de Henares: Institución de Estudios Complutenses, 1998. p. 401-410.

COVARRUBIAS, Sebastián. Tesoro de la lengua castellana o española. Madrid: Turner, 1984.

DADSON, Trevor J. Libros, lectores y lecturas: estudios sobre bibliotecas particulares españolas del Siglo de Oro. Madrid: Arco/Libros, 1998

DICCIONARIO de Autoridades. Madrid: Gredos, 1990.

ESCARTÍ, Vicent J. Memòria privada: literatura memorialística valenciana del segle XV al XVIII. València: Eliseu Climent Editor, 1998.

FOISIL, Madeleine. La escritura del ámbito privado. In: ARIÈS, Philippe; DUBY, Georges (Dir.); ARIÈS, Philippe; CHARTIER, Roger (Org.). Historia de la vida privada, $t$. 5: el proceso de cambio en la sociedad de los siglos XVI-XVIII. Madrid: Taurus, 1991.

FRANCESCHINI, F. La mémoire des laboratores à Florence au début du $\mathrm{XV}^{\mathrm{e}}$ siècle. Annales, 5, p. 1143-1167, 1990.

GARCÍA CÁRCEL, Ricardo. De la memoria personal a la memoria colectiva: algunas reflexiones. Hispanistica XX, 10, p. 3-13, 1993.

GARCÍA GARCÍA, Bernardo J. La Pax Hispánica: política exterior del Duque de Lerma, Leuven: Leuven Univesity Press, 1996.

GONZALO SÁNCHEZ-MOLERO, José Luis. Regia Bibliotheca: los libros en la corte española de Carlos V. Mérida: Editora Regional de Extremadura, 2004. 
GÜIJO, Gregorio M. de. Diario, 1648-1664. Ed. Manuel Romero de Terrero. México: Porrua, 1952.

KLAPISCH-ZUBER, Christine. Comptes et mémoire: l'écriture des livres de famille florentins. In: BOURLET, C.; DUFOUR, A. (Ed.). L'écrit dans la société médiévale: divers aspects de sa pratique du $\mathrm{XI}^{\mathrm{e}}$ au $\mathrm{XVI}^{\mathrm{e}}$ siècle. Textes en hommage à L. Fossier. Paris: CNRS, 1991. p. 251-258.

LALOU, Elisabeth (Ed.). Les tablettes à écrire de l'Antiquité à l'époque moderne. In: Colloque international du CNRS, 1990, Paris. Actes... Turnhout: Brepols, 1992.

LEJEUNE, Philippe; BOGAERT, Catherine. Un journal à soi: histoire d'une pratique. Paris: Textuel, 2003.

LIÑÁN Y VERDUGO, Antonio. Guía y aviso de forasteros que vienen a la Corte. Edición de Edisons Simons. Madrid: Editora Nacional, 1980. MANDINGORRA LLAVATA, María Luz. La configuración de la identidad privada: diarios y libros de memorias en la baja Edad Media. In: CASTILLO GÓMEZ, Antonio (Coord.). La conquista del alfabeto: escritura y clases populares. Gijón: Trea, 2002. p. 131-152.

MONTAIGNE, Michel de. Ensayos. Edición y traducción de Mª. Dolores Picazo y Almudena Montojo. Madrid: Cátedra, 1985.

MORDENTI, Raul. I libri di famiglia in Italia, II: Geografia e Storia. In Appendice gli Atti del Seminario nazionale "I libri di famiglia in Italia: quindici anni di ricerche” (Roma Tor Vergata, 27-28 giugno 1997). Roma: Edizioni di Storia e Letteratura, 2001.

NAVARRO BONILLA, Diego. El proceso de inventario de escrituras: fuente documental para una historia social de la cultura escrita en Aragón. In: CONGRÉS D'HISTÒRIA DE LA CORONA D'ARAGÓ, 17., 2000, Barcelona-Lleida. El món urbà a la corona d'Aragó del 1137 als decrets de Nova Planta. Barcelona: Universitat de Barcelona, 2003. v. 2, p. 807816.

OPLL, Ferdinand; RUDOLF, Karl F. España y Austria. Madrid: Cátedra, 1997.

PEÑA, Manuel. Cataluña en el Renacimiento: libros y lenguas (Barcelona, 1473-1600). Lleida: Milenio, 1996.

PEÑALOSA, Nicolás de. Sermón que predicó... en la Sancta Iglesia de Cartagena a las honras que hizo la... Ciudad de Murcia al Rey... Philipe Tercero a seys de Mayo jueves 1621. [s.l.]: [s.n.], [s.d.]. 
PEPYS, Samuel. Diarios (1660-1669). Trad. Norah Lacoste. Sevilla: Renacimiento, 2003.

PETRUCCI, Armando. Scrittura, alfabetismo ed educazione grafica nella Roma del primo Cinquecento: da un libretto di conti di Maddalena pizzicarola in Trastevere. Scrittura e Civiltà, 2, p. 163-207, 1978.

PLADEVALL I FONT, Antoni; SIMON I TARRÉS, Antoni. Guerra i vida pagesa a la Catalunya del segle XVII: segons el "Diari” de Joan Guàrdia, pagès de l'Esquirol, i altres testimonis d’Osona. Barcelona: Curial Edicions, 1986.

PORCAR, Joan. Coses evengudes en la ciutat i regne de València. Ed. Vicente Castañeda Alcover. Madrid, 1934.

RODRÍGUEZ-SAN PEDRO BEZARES, Luis E. Vida, aspiraciones y fracasos de un estudiante de Salamanca: el diario de Gaspar Ramos Ortiz (1568-1569). Salamanca: Ediciones Universidad de Salamanca, 1999.

ROJO VEGA, Anastasio. El Siglo de Oro: inventario de una época. Valladolid: Junta de Castilla y León, Consejería de Educación y Cultura, 1996.

SÁNCHEZ CANTÓN, Francisco Javier. Inventarios reales: bienes muebles que pertenecieron a Felipe II. Madrid: Real Academia de la Historia, 1956-1959.

SIGÜENZA, Fray José de. La fundación del monasterio de El Escorial. Madrid: Aguilar, 1988.

SIMON I TARRES, Antoni. Cavallers i ciutadans a la Catalunya del Cinc-Cents. Barcelona: Curial Edicions, 1991.

SLICHER VAN BATH, B. H. Accounts and diaries of farmers before 1800 as sources for agricultural history. A.A.G. Bijdragen, 8, p. 5-33, 1962.

SOLÍS, Antonio de. El doctor Carlino. In: DRAMÁTICOS posteriores a Lope de Vega. Madrid: Atlas, 1951. (Biblioteca de Autores Españoles, 47). SOMMAIA, Girolamo. Diario de un estudiante de Salamanca: la crónica inédita de Girolamo da Sommaia (1603-1607). Edición de Georges Haley. Salamanca: Universidad de Salamanca, 1977.

STOKLUND, B. On Interpreting Peasant Diaries: Material Life and Collective Consciousness. Ethnologia Europaea, 11, p. 191-207, 1980.

TASSA de los precios a que se han de vender las mercaderías y otras cosas de que no se hizo mención en la primera tassa y reformación que aora se ha hecho por los señores del Consejo en algunos precios que se pusieron en 
ella. Madrid: Juan González, 1628.

TERRADAS I SABORIT, Ignasi. El món històric de les masies: conjectures generals i casos particulars. Barcelona: Curial, 1984.

TORRE Y DEL CERRO, Antonio de la. Testamentaría de Isabel la Católica. Barcelona, 1974.

TORRES SANS, Xavier. Els llibres de família de pagès (segles XVI$X V I I I)$ : memòries de pagès, memòries de mas. Girona: CCG Edicions, 2000. TRICARD, J. Quést-ce qu'un livre de raison limousnin du $\mathrm{XV}^{\mathrm{e}}$ siècle?. Journal des Savants, s/ n., p. 263-276, 1988.

VEGA, Lope de. El premio de la hermosura. In: OBRAS escogidas, III: teatro, v. II. Ed. Federico C. Sáinz de Robles. 3ª ed. Madrid: Aguilar, 1981. YCÍAR, Juan. Ortographía prática. Zaragoza: Bartolomé de Nágera, 1548.

ZAPATA, Luis de. Miscelánea. Madrid: Imprenta Nacional, 1959. (Memorial Histórico Español, XI). 